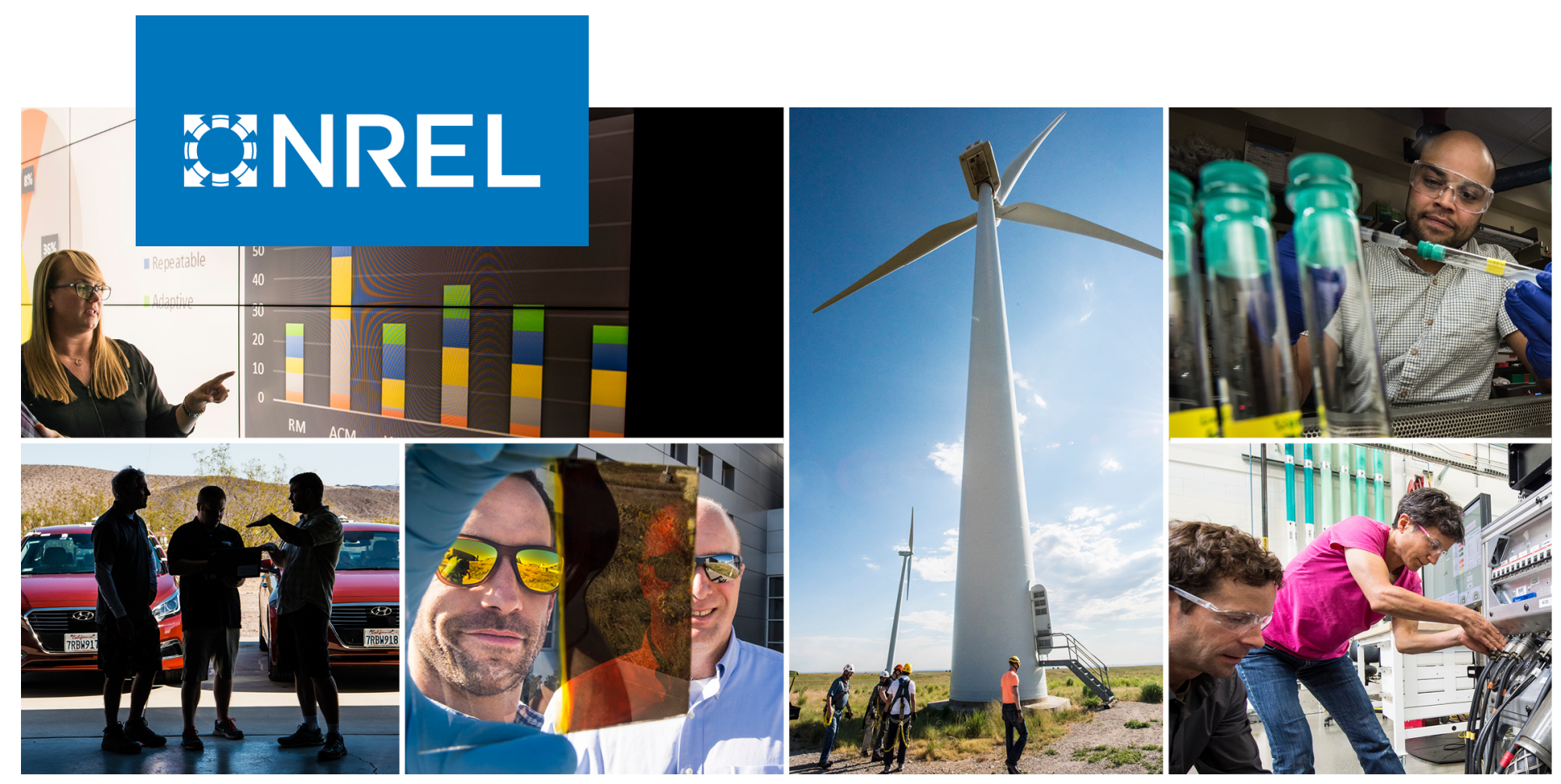

\title{
Tuning of Nacelle Feedback Gains for Floating Wind Turbine Controllers using a Two-DOF Model
}

\section{Preprint}

Eben Lenfest, ${ }^{1}$ Andrew J. Goupee, ${ }^{1}$ Alan Wright, ${ }^{2}$ and Nikhar Abbas ${ }^{2}$

1 University of Maine

2 National Renewable Energy Laboratory

Presented at the ASME $20203^{\text {th }}$ International Conference on Ocean, Offshore and Arctic Engineering

August 3-7, 2020

NREL is a national laboratory of the U.S. Department of Energy

Office of Energy Efficiency \& Renewable Energy

Operated by the Alliance for Sustainable Energy, LLC

This report is available at no cost from the National Renewable Energy Laboratory (NREL) at www.nrel.gov/publications.
Conference Paper

NREL/CP-5000-76558

September 2020 


\title{
BNREL
}

\section{Tuning of Nacelle Feedback Gains for Floating Wind Turbine Controllers using a Two-DOF Model}

\section{Preprint}

\author{
Eben Lenfest, ${ }^{1}$ Andrew J. Goupee, ${ }^{1}$ Alan Wright, ${ }^{2}$ and \\ Nikhar Abbas ${ }^{2}$
}

1 University of Maine

2 National Renewable Energy Laboratory

\section{Suggested Citation}

Lenfest, Eben, Andrew J. Goupee, Alan Wright, and Nikhar Abbas. 2020. Tuning of Nacelle Feedback Gains for Floating Wind Turbine Controllers using a Two-DOF Model: Preprint. Golden, CO: National Renewable Energy Laboratory. NREL/CP-5000-76558. www.nrel.gov/docs/fy20osti/77508.pdf.

NREL is a national laboratory of the U.S. Department of Energy Office of Energy Efficiency \& Renewable Energy Operated by the Alliance for Sustainable Energy, LLC

This report is available at no cost from the National Renewable Energy Laboratory (NREL) at www.nrel.gov/publications.

Contract No. DE-AC36-08GO28308
Conference Paper

NREL/CP-5000-76558

September 2020

National Renewable Energy Laboratory 15013 Denver West Parkway Golden, CO 80401 303-275-3000 • www.nrel.gov 


\section{NOTICE}

This work was authored [in part] by the National Renewable Energy Laboratory, operated by Alliance for Sustainable Energy, LLC, for the U.S. Department of Energy (DOE) under Contract No. DE-AC36-08GO28308. Funding provided by the U.S. Department of Energy Office of Energy Efficiency and Renewable Energy Wind Energy Technologies Office. The views expressed herein do not necessarily represent the views of the DOE or the U.S. Government. The U.S. Government retains and the publisher, by accepting the article for publication, acknowledges that the U.S. Government retains a nonexclusive, paid-up, irrevocable, worldwide license to publish or reproduce the published form of this work, or allow others to do so, for U.S. Government purposes.

This report is available at no cost from the National Renewable Energy Laboratory (NREL) at www.nrel.gov/publications.

U.S. Department of Energy (DOE) reports produced after 1991 and a growing number of pre-1991 documents are available free via www.OSTI.gov.

Cover Photos by Dennis Schroeder: (clockwise, left to right) NREL 51934, NREL 45897, NREL 42160, NREL 45891, NREL 48097, NREL 46526.

NREL prints on paper that contains recycled content. 


\section{TUNING OF NACELLE FEEDBACK GAINS FOR FLOATING WIND TURBINE CONTROLLERS USING A TWO-DOF MODEL}

\author{
Eben Lenfest \\ University of Maine \\ Orono, ME \\ Alan Wright \\ National Renewable Energy Laboratory \\ Boulder, CO
}

\author{
Andrew J. Goupee \\ University of Maine \\ Orono, ME
}

\author{
Nikhar Abbas \\ National Renewable Energy Laboratory \\ Boulder, CO
}

\begin{abstract}
Designing a collective blade pitch controller for floating offshore wind turbines (FOWTs) poses unique challenges due to the interaction of the controller with the dynamics of the platform. The controller must also handle the competing objectives of power production performance and fatigue load management. Existing solutions either detune the controller with the result of slowed response, make use of complicated tuning methods, or incorporate a nacelle velocity feedback gain. With the goal of developing a simple control tuning method for the general FOWT researcher that is easily extensible to a wide array of turbine and hull configurations, this last idea is built upon by proposing a simple tuning strategy for the feedback gain. This strategy uses a two degreeof-freedom (DoF) turbine model that considers tower-top foreaft and rotor angular displacements. For evaluation, the nacelle velocity term is added to an existing gain scheduled proportional-integral controller as a proportional gain. The modified controller is then compared to baseline land-based and detuned controllers on an example system for several load cases. First-pass results are favorable, demonstrating how researchers can use the proposed tuning method to efficiently schedule gains for adequate controller performance as they investigate new FOWT configurations.
\end{abstract}

Keywords: Floating Offshore Wind Turbine, Collective Blade Pitch Control, OpenFAST

\section{NOMENCLATURE}

$\bar{C}_{F O W T} \quad$ FOWT pitch damping (radiation plus linearized viscous)

$I_{\text {drive }} \quad$ Combined rotor and drivetrain rotational inertia

$\bar{I}_{\text {FOWT }}$

$\bar{K}_{\text {FOWT }}$

$k_{i}$

$k_{p}$

$k_{p x}$

$L_{h h}$

$M_{y}$

$P$

Qaero

$Q_{\text {gen,lss }}$ $s_{i}$

$T_{\text {aero }}$

$v$

$x$

$\beta$

$\Delta \varsigma_{x}$

$\theta$

$\phi$

$\omega$

$\omega_{n, \text { rot,des }}$

$\Omega$

Srot,des
FOWT pitch inertia (physical and added) FOWT pitch stiffness (hydrostatic plus mooring) Integral gain on rotor speed error Proportional gain on rotor speed error Proportional gain on tower-top velocity Hub height as measured from platform pitch axis Tower-base pitching moment

Generator power

Aerodynamic torque

Generator torque cast at the low-speed shaft $i^{\text {th }}$ system pole

Aerodynamic thrust

Wind velocity

Tower-top fore-aft displacement

Blade pitch angle

Additional tower-top feedback FOWT damping FOWT pitch angle

Rotor angular displacement

Forcing frequency

Controller design frequency

Rotor angular velocity

Controller design damping ratio 


\section{INTRODUCTION}

The drive to make wind power more affordable relative to traditional power sources has led to the advent of offshore wind farms, which benefit from proximity to population centers and strong, steady ocean winds. A recent focus has been on floating offshore wind turbines (FOWTs), which would allow for the placement of farms in locations too deep for existing fixedbottom foundations. One of the difficulties with this type of foundation is adapting the blade pitch controller for the wind turbine, which is now tasked with both maximizing power output and attempting to stabilize the structure to avoid fatigue.

A product of these competing objectives is known as the negative damping problem [1], [2]. When a turbine is mounted on a floating platform, the nacelle translates forward and backward relative to the wind. As the nacelle moves forward, its velocity relative to the wind increases. This causes the pitch controller to feather the blades slightly to reduce generator speed. The thrust force on the turbine is thereby reduced, further accelerating the nacelle forward. The inverse effect is seen as the nacelle moves backward. The rigid-body pitch (or in the case of tension leg platforms, surge) natural frequency of the platform can be excited through these oscillations, reducing the stability of the system.

There are several proposed solutions for tackling this issue. The most basic of these, proposed by Larsen and Hanson [2], is to detune the gains of the blade pitch controller until it can no longer respond fast enough to excite the platform motion. While platform pitching is reduced using this control scheme, it can lead to poor power regulation.

Feedforward control has also been used to address the issue; LiDAR can be used to detect incoming wind and set blade pitch accordingly [3]. Investigations into the implementation of LiDAR have mostly returned positive results. Studies by Schlipf et al. ([4] and [5]) and Navalkar et al. [6] all found that predictive control reduces power and generator speed variations while simultaneously decreasing loads on the tower, shaft, and blades.

Many other approaches to floating wind turbine control have been explored, of varying degrees of complexity. Magar and Balas [7] implemented an adaptive, individual blade-pitch controller that feeds back platform pitch, and found that it outperformed baseline controllers but could not guarantee stability. Lemmer et al. [8] consider the benefits of supplanting traditional proportional-integral (PI) controllers with an optimized Linear Quadratic Regulator (LQR). The LQR is found to be superior at managing platform motions and resonance. In another study, an adaptive state feedback controller was designed to accommodate change in the first tower natural frequency due to aging [9]. Fatigue loads on the support structure were reduced by 3\%. The work of Kakita et al. [10] involves finding the optimum gains for a traditional PI controller using the Fictitious Reference Iterative Tuning (FRIT) approach. Generator speed and platform pitching were improved over the baseline, but pitch actuation increased significantly.
One other option for eliminating the instability is to estimate the absolute wind speed by providing feedback to the controller in the form of the nacelle velocity or acceleration. This was explored by Fischer [11], who found reduced platform pitching and rotor overspeed but increased drivetrain loads. Fischer and Loepelmann [12] later found that by feeding back a reduced frequency range to the generator torque controller, these loads could be decreased. Another study [13] found similar improvements in tower bending loads. Lackner [14] made the rotor speed setting a variable of nacelle velocity, resulting in better platform stability but more rotor speed variation. A controller developed by Skaare et al. [15] focused on extending platform fatigue life, and did so by at least $86 \%$ at the expense of a $3.8 \%$ reduction in power output relative to a conventional controller.

While there are a wealth of options for blade pitch controller tuning, the gap that this work hopes to address is to produce a simple method for generating controller gains that will provide adequate performance in both power and pitch regulation for researchers who don't necessarily specialize in controls. Something like this might therefore be useful to integrate into a controller design tool like ROSCO [16]. This tuning approach will utilize feedback of nacelle velocity, as it is relatively easy to implement, does not require feedforward control hardware, and has seen promising results in past research. The controller presented here is focused on region 3, which spans from rated wind speed to cut-out wind speed.

\section{CONTROLLER TUNING METHODOLOGY}

In this work, a tuning methodology for a basic collective blade pitch wind turbine controller employing tower-top feedback in region 3 is proposed for use in floating wind turbines with compliant foundations. The controller architecture is identical to that presented in [1], albeit, the tower-top feedback gain is scheduled with blade pitch angle instead of being constant. The generator torque is held constant.

For the proposed tuning strategy, a two degree-of-freedom (DoF) model is developed that is used to inform the scheduling of the controller gains. This is done to achieve rotor speed control similar to land-based turbines without significantly increasing blade pitch actuation motion, while simultaneously reducing platform pitch motion compared to other basic floating offshore wind turbine control tuning strategies like those employed in [17]. The model considers only the rotor speed angular motion $(\phi)$ and platform pitch angular motion $(\theta)$, as shown in Figure 1, as these are the DoF most strongly influenced by the collective blade pitch controller actions.

The equations of motion for the two DoF are derived in a similar manner to that found in [18] for the rotor angular motion and [1] for the platform pitch motion. However, all terms that couple the DoF are retained in order to develop a more robust model that provides better predictions of floating wind turbine behavior, and hence, a better tool for use in scheduling controller gains to achieve improved floating wind turbine performance. 


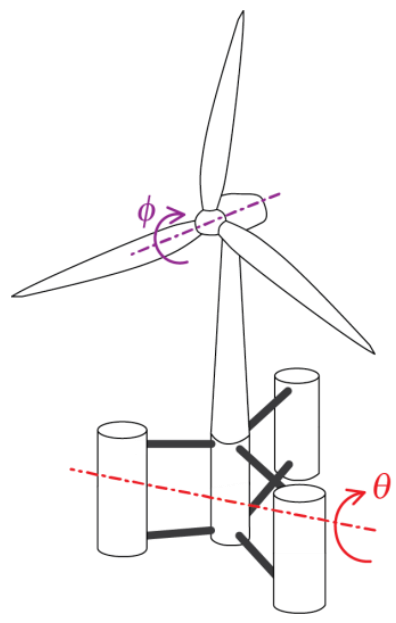

FIGURE 1: DEGREES OF FREEDOM IN CONTROLLER TUNING MODEL

\section{Two Degree-of-Freedom Model}

To begin, the angular equation of motion for the drivetrain about the low-speed shaft is written as

$$
I_{\text {drive }} \frac{d}{d t}\left(\Omega_{o}+d \Omega\right)=I_{\text {drive }} d \dot{\Omega}=Q_{a e r o}-Q_{g e n, l s s}
$$

where $\Omega_{o}$ is the rated low-speed shaft angular velocity. The aerodynamic torque is a function of blade pitch and rotor speed, as noted by Jonkman [18]. Linearizing about the operating point yields

$$
\begin{gathered}
I_{\text {drive }} d \dot{\Omega}=Q_{\text {aero }}-Q_{g e n, l s s} \cong Q_{o}+\frac{\partial Q}{\partial \Omega} d \Omega+\frac{\partial Q}{\partial \beta} d \beta+ \\
\frac{\partial Q}{\partial v}(d v-\dot{x})-Q_{g e n, l s s}
\end{gathered}
$$

where $Q_{o}$ is the mean aerodynamic torque at the operating point and the partial derivatives represent the sensitivity of the aerodynamic torque to changes in rotor angular velocity, blade pitch angle and wind speed. The sensitivity of the aerodynamic torque to a change in wind speed is multiplied not only by a change in wind speed $d v$, but also the apparent wind speed due to the tower-top's own velocity, $\dot{x}$. The platform pitch angle is assumed to be small when determining $\dot{x}$. Noting that the mean aerodynamic torque is equal to the generator torque, which is taken as constant in region 3 here, gives

$I_{\text {drive }} d \dot{\Omega} \cong \frac{\partial Q}{\partial \Omega} d \Omega+\frac{\partial Q}{\partial \beta} d \beta+\frac{\partial Q}{\partial v}(d v-\dot{x})$.

The following sensitivity quantities are defined,

$A_{\Omega}=\frac{\partial Q}{\partial \Omega}, A_{\beta}=\frac{\partial Q}{\partial \beta}, A_{v}=\frac{\partial Q}{\partial v}$

to be evaluated at the operating point. The definitions are then substituted into Eq. 3 to yield
$I_{\text {drive }} d \dot{\Omega} \cong A_{\Omega} d \Omega+A_{\beta} d \beta+A_{v}(d v-\dot{x})$

The platform pitch equation of motion in the absence of wave forcing is written as

$\bar{I}_{F O W T} \ddot{\theta}+\bar{C}_{F O W T} \dot{\theta}+\bar{K}_{F O W T} \theta=T_{a e r o} L_{h h}$.

Note that the equations of motion are written about the point on the structure at which there is no mass/inertia coupling (inclusive of added mass and inertia). The hydrostatic stiffness employed includes both hydrostatic and mooring stiffnesses, and is selected to produce the correct platform pitch natural frequency. To continue, the tower-top fore-aft displacement and platform angular displacement are related as

$\boldsymbol{x}=\boldsymbol{L}_{\boldsymbol{h} h} \boldsymbol{\theta}$,

which when substituted into Eq. 6 yields

$\frac{\bar{I}_{F O W T}}{L_{h h}^{2}} \ddot{x}+\frac{\bar{C}_{F O W T}}{L_{h h}^{2}} \dot{x}+\frac{\bar{K}_{F O W T}}{L_{h h}^{2}} x=T_{\text {aero }}$.

Defining the following FOWT properties

$I_{F O W T}=\frac{\bar{I}_{F O W T}}{L_{h h}^{2}}, C_{F O W T}=\frac{\bar{C}_{F O W T}}{L_{h h}^{2}}, K_{F O W T}=\frac{\bar{K}_{F O W T}}{L_{h h}^{2}}$,

and substituting the three quantities into Eq. 8 gives

$I_{\text {FOWT }} \ddot{x}+C_{F O W T} \dot{x}+K_{F O W T} x=T_{\text {aero }}$.

Linearizing the aerodynamic thrust about the operating point gives

$$
\begin{aligned}
I_{F O W T} \ddot{x}+C_{F O W T} \dot{x}+K_{F O W T} x & =T_{a e r o} \\
& \cong T_{o}+\frac{\partial T}{\partial \Omega} d \Omega+\frac{\partial T}{\partial \beta} d \beta+\frac{\partial T}{\partial v}(d v-\dot{x}),
\end{aligned}
$$

which upon utilization of the following thrust sensitivity definitions

$B_{\Omega}=\frac{\partial T}{\partial \Omega}, B_{\beta}=\frac{\partial T}{\partial \beta}, B_{v}=\frac{\partial T}{\partial v}$,

yields

$$
\begin{aligned}
& I_{F o W T} \ddot{x}+C_{F o W T} \dot{x}+K_{F o W T} x \\
& \cong T_{o}+B_{\Omega} d \Omega+B_{\beta} d \beta+B_{v}(d v-\dot{x}) .
\end{aligned}
$$

To eliminate the mean thrust at the operating point, the towertop motion about the static equilibrium position due to the thrust $T_{o}$ is defined as

$y=x-\frac{T_{o}}{K_{F O W T}}$.

Substitution of Eq. 14 into Eq. 13 results in 


$$
\begin{aligned}
& I_{F o W T} \ddot{y}+C_{F o W T} \dot{y}+K_{F O W T} y \\
& \cong B_{\Omega} d \Omega+B_{\beta} d \beta+B_{v}(d v-\dot{y})
\end{aligned}
$$

The control equation used for this system computes the desired change in blade pitch angle $d \beta$ as

$d \beta=k_{p} d \Omega+k_{i} \int_{0}^{t} d \Omega d t+k_{p x} \dot{x}$.

The control equation consists of a standard proportionalintegral controller targeting rotor speed error $d \Omega$ and is supplemented with an additional term proportional to the tower-top fore-aft velocity. Noting that the rotor angular displacement and angular velocity are related as

$\dot{\phi}=d \Omega$,

and substituting the control equation into Eq. 5, the drivetrain angular equation of motion, gives

$$
\begin{aligned}
& I_{\text {drive }} \ddot{\phi}-\left(A_{\Omega}+A_{\beta} k_{p}\right) \dot{\phi}-A_{\beta} k_{i} \phi+\left(A_{v}-A_{\beta} k_{p x}\right) \dot{x} \\
& \quad \cong A_{v} d v
\end{aligned}
$$

Substitution of the control equation into the platform pitch equation of motion, Eq. 15, yields

$$
\begin{gathered}
I_{F O W T} \ddot{y}+\left(C_{F o W T}+B_{v}-B_{\beta} k_{p x}\right) \dot{y}+K_{F o w T} y- \\
\left(B_{\Omega}+B_{\beta} k_{p}\right) \dot{\phi}-B_{\beta} k_{i} \phi \cong B_{v} d v
\end{gathered}
$$

Representing Eq. 18 and Eq. 19 in matrix equation form yields the following two-DoF coupled equations of motion,

$$
\begin{aligned}
& {\left[\begin{array}{cc}
I_{\text {FOWT }} & 0 \\
\mathbf{0} & \boldsymbol{I}_{\text {drive }}
\end{array}\right]\left\{\begin{array}{l}
\ddot{y} \\
\ddot{\phi}
\end{array}\right\}+} \\
& {\left[\begin{array}{cc}
\left(C_{F o w T}+B_{v}-B_{\beta} k_{p x}\right) & -\left(B_{\Omega}+B_{\beta} k_{p}\right) \\
\left(A_{v}-A_{\beta} k_{p x}\right) & -\left(A_{\Omega}+A_{\beta} k_{p}\right)
\end{array}\right]\left\{\begin{array}{l}
\dot{y} \\
\dot{\phi}
\end{array}\right\}+} \\
& {\left[\begin{array}{cc}
K_{\text {FoWT }} & -B_{\beta} k_{i} \\
0 & -A_{\beta} k_{i}
\end{array}\right]\left\{\begin{array}{l}
y_{\phi} \\
\text { o }
\end{array}\right\} \cong\left\{\begin{array}{l}
B_{v} \\
A_{v}
\end{array}\right\} d v \text {. }}
\end{aligned}
$$

The natural frequencies and damping ratios can be obtained from the two-DoF model by first considering the free vibration problem, which has the form

$$
\begin{aligned}
& {\left[\begin{array}{cc}
\boldsymbol{I}_{\text {FOWT }} & \mathbf{0} \\
\mathbf{0} & \boldsymbol{I}_{\text {drive }}
\end{array}\right]\left\{\begin{array}{l}
\ddot{y} \\
\ddot{\boldsymbol{\phi}}
\end{array}\right\}+} \\
& {\left[\begin{array}{cc}
\left(\boldsymbol{C}_{\text {FowT }}+\boldsymbol{B}_{v}-\boldsymbol{B}_{\beta} \boldsymbol{k}_{p x}\right) & -\left(\boldsymbol{B}_{\Omega}+\boldsymbol{B}_{\beta} \boldsymbol{k}_{p}\right) \\
\left(\boldsymbol{A}_{v}-\boldsymbol{A}_{\beta} \boldsymbol{k}_{p x}\right) & -\left(\boldsymbol{A}_{\Omega}+\boldsymbol{A}_{\beta} \boldsymbol{k}_{p}\right)
\end{array}\right]\left\{\begin{array}{c}
\dot{\boldsymbol{y}} \\
\dot{\boldsymbol{\phi}}
\end{array}\right\}+} \\
& {\left[\begin{array}{cc}
K_{\text {FOWT }} & -B_{\beta} \boldsymbol{k}_{i} \\
\mathbf{0} & -A_{\beta} \boldsymbol{k}_{i}
\end{array}\right]\left\{\begin{array}{l}
\boldsymbol{y} \\
\phi
\end{array}\right\} \cong\left\{\begin{array}{l}
\mathbf{0} \\
0
\end{array}\right\} \text {. }}
\end{aligned}
$$

Next, the following assumptions are made for the solutions of the tower-top fore-aft and rotor angular motions [19], $\left\{\begin{array}{l}y(t) \\ \phi(t)\end{array}\right\}=\left\{\begin{array}{l}Y \\ \Phi\end{array}\right\} e^{s t}$,

where $Y, \Phi$, and $s$ are constants. Substitution of Eq. 22 into Eq. 21 gives

$$
\begin{aligned}
& {\left[\begin{array}{cc}
s^{2} R_{11}+s R_{12}+R_{13} & s R_{21}-R_{22} \\
s R_{31} & s^{2} R_{41}+s R_{42}-R_{43}
\end{array}\right]\left\{\begin{array}{l}
Y \\
\Phi
\end{array}\right\} \cong\left\{\begin{array}{l}
0 \\
0
\end{array}\right\},} \\
& R_{11}=I_{F O W T} \\
& R_{12}=C_{F O W T}+B_{v}-B_{\beta} k_{p x} \\
& R_{13}=K_{F O W T} \\
& R_{21}=-B_{\Omega}-B_{\beta} k_{p} \\
& R_{22}=-B_{\beta} k_{i} \\
& R_{31}=A_{v}-A_{\beta} k_{p x} \\
& R_{41}=I_{d r i v e} \\
& R_{42}=-A_{\Omega}-A_{\beta} k_{p} \\
& R_{43}=-A_{\beta} k_{i}
\end{aligned}
$$

The determinant of the $2 \times 2$ coefficient matrix of Eq. 23 is set to zero, which yields a characteristic equation of the form

$$
\left(s-s_{1}\right)\left(s-s_{2}\right)\left(s-s_{3}\right)\left(s-s_{4}\right)=0,
$$

where $s_{1}, s_{2}, s_{3}$ and $s_{4}$ are the four roots of the characteristic equation. These four roots also constitute the system poles [20], two predominantly associated with the platform angular motion DoF and the other two primarily associated with the rotor angular motion DoF. These poles can be used to determine estimates for the natural frequencies and damping ratios for the rotor angular and platform pitch motions.

\section{Scheduling of Controller Gains}

In this section, the simplistic approach with which the collective blade pitch wind turbine controller gains are scheduled with blade pitch angle is presented. To begin, the proportional and integral gains are tuned in a manner similar to the NREL ROSCO controller [16]. The proportional gain $k_{p}$ and integral gain $k_{i}$ are determined as

$k_{p}=-2 A_{\beta}^{-1}\left(A_{\Omega}+I_{\text {drive }} S_{\text {rot }, \text { des }} \omega_{n, \text { rot }, \text { des }}\right)$,
$k_{i}=-A_{\beta}^{-1} I_{\text {drive }} \omega_{n, \text { rot }, \text { des }}^{2}$,

where $\omega_{n, r o t, d e s}$ and $\zeta_{\text {rot,des }}$ are the controller design natural frequency and design damping ratio for the rotor angular motion. The aerodynamic sensitivities vary with the wind speed, and hence the corresponding blade pitch angle. The aerodynamic sensitivities required for scheduling the gains are obtained from linearization analyses in OpenFAST [21]. The linearization analyses are conducted for several wind speeds ranging from rated wind speed to cut-out wind speed, and the obtained sensitivities are smoothed using a quadratic polynomial fit prior to insertion into Eq. 25 for determining the gain schedules. This produces a smooth set of control gain schedules for use in the wind turbine controller. 
With the proportional and integral gains determined, the remaining tower-top feedback gain $k_{p x}$ is scheduled by utilizing the previously described two-DoF model. For a given wind speed with the associated aerodynamic sensitivities and associated gains $k_{p}$ and $k_{i}$, the gain $k_{p x}$ is solved for such that a specified increase in the platform pitch damping, $\Delta \zeta_{p i t}$, is achieved over the case where $k_{p x}=0$. This is repeated multiple times across the range of wind speeds in region 3 , from rated to cut-out, in order to determine the scheduling of the gain $k_{p x}$. As is done in the first step of this tuning procedure, all aerodynamic sensitivities used are determined from OpenFAST linearization analyses and smoothed with a quadratic polynomial fit prior to use in the two-DoF model. It should be noted that there is a limit to the increase in platform damping that can be achieved using active blade pitch control, and as such, it is suggested that modest values of $\Delta \zeta_{p i t}$ be used to achieve reasonable results ( $3 \%$ was found to work well in the case examined here).

To complete the controller, which is implemented using the MATLAB Simulink option in OpenFAST, the tower-top foreaft velocity signal is filtered to isolate the motion near the platform pitch natural frequency for use in the controller. A second-order band-pass filter is implemented as per [22], the transfer function of which is described as

$H(s)=\frac{(2 \Delta \omega) s}{s^{2}+(2 \Delta \omega) s+\omega_{n, p i t}^{2}}$

where $\Delta \omega$ is a deviation from the pitch natural frequency where the signal will be reduced by three decibels and $\omega_{n, p i t}$ is the platform pitch natural frequency.

\section{SYSTEM PARTICULARS}

To demonstrate the performance of the proposed control scheme, the popular DeepCwind OC4 semisubmersible floating wind turbine model was utilized, shown in Figure 2. The description of the system particulars required to model the system in OpenFAST, which is undertaken later in this work, can be found in [17] and [20]. This floating wind turbine system was chosen because the specifications are well detailed and the global performance of this particular arrangement has been extensively examined in other works.

From [17] and [20], the inputs required for the two-DoF model of Eq. 23 can be derived. The values used are provided in Table 1. Recall that the platform pitch inertia includes both physical and added inertia and corresponds to the location on the structure where surge and pitch mass coupling does not occur. The platform rotational stiffness is selected to give the correct platform pitch natural frequency as computed from a full OpenFAST simulation, and the linearized platform hydrodynamic damping is assumed to be $5 \%$ of critical (which is reasonable based on DeepCwind test data [23]). The hub height $L_{h h}$ is measured positive upward from this pitch axis location.

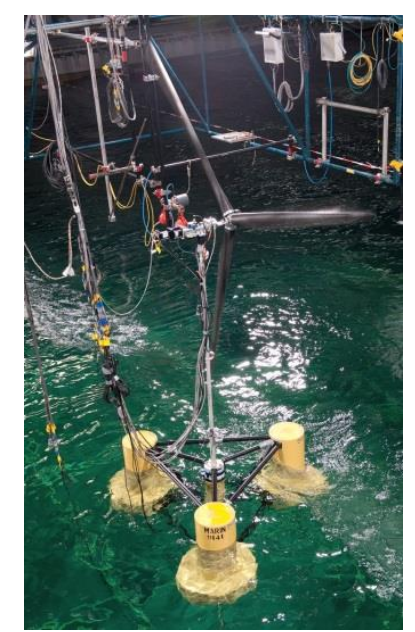

FIGURE 2: IMAGE OF DEEPCWIND OC4 SEMISUBMERSIBLE

TABLE 1: TWO-DOF MODEL INPUTS

\begin{tabular}{|l|l|}
\hline Quantity & Value \\
\hline $\bar{I}_{\text {FOWT }}$ & $1.75 \times 10^{10} \mathrm{~kg} \mathrm{~m}^{2}$ \\
\hline $\bar{C}_{\text {FOWT }}$ & $4.35 \times 10^{8} \mathrm{~N} \mathrm{~m} \mathrm{~s}$ \\
\hline $\bar{K}_{\text {FOWT }}$ & $1.08 \times 10^{9} \mathrm{~N} \mathrm{~m}$ \\
\hline$L_{\text {hh }}$ & $100.9 \mathrm{~m}$ \\
\hline$I_{\text {drive }}$ & $4.38 \times 10^{7} \mathrm{~kg} \mathrm{~m}^{2}$ \\
\hline
\end{tabular}

\section{TEST CONDITIONS}

The environmental conditions used in full time-domain OpenFAST simulations are outlined in Table 2. The conditions were modeled after IEC DLC 1.2 for the Gulf of Maine. All winds and waves were collinear with no current. The wind fields were generated in TurbSim using the Kaimal spectrum and a normal turbulence model with class A intensity. Eighteen seeds of each load case were simulated, and 600 seconds of data were recorded after a 250 -second lead-in time to eliminate transients.

TABLE 2: SIMULATED ENVIRONMENTAL CONDITIONS

\begin{tabular}{|l|l|l|l|}
\hline $\begin{array}{l}\text { Mean Wind } \\
\text { Speed }(\mathrm{m} / \mathrm{s})\end{array}$ & $\begin{array}{l}\text { Sig. Wave } \\
\text { Height }(\mathrm{m})\end{array}$ & $\begin{array}{l}\text { Peak Wave } \\
\text { Period }(\mathrm{s})\end{array}$ & $\begin{array}{l}\text { JONSWAP } \\
\text { Gamma }\end{array}$ \\
\hline 12 & 1.21 & 7.30 & 1.6 \\
\hline 18 & 2.05 & 8.12 & 1.7 \\
\hline
\end{tabular}

The twelve meter per second condition was selected because the platform pitch instability is most prominent just after rated wind speed [24]. The eighteen meter per second condition was selected as it is near the middle of region 3 for the NREL 5-MW wind turbine. In addition to varying the environments, two traditional controllers were used along with the proposed controller for the sake of comparison when simulating the response of the DeepCwind OC4 semisubmersible. These controllers were tuned by using

$k_{p}=-2 A_{\beta}^{-1}\left(I_{\text {drive }} \varsigma_{\text {rot,des }} \omega_{n, \text { rot }, \text { des }}\right)$,

$\boldsymbol{k}_{i}=-A_{\beta}^{-1} I_{\text {drive }} \omega_{n, \text { rot }, \text { des }}^{2}$, 
as outlined in [18]. The list of controllers used in this work is provided in Table 3.

TABLE 3: CONTROLLER DEFINITIONS

\begin{tabular}{|l|l|}
\hline Controller & Description \\
\hline 1 & $\begin{array}{l}\text { Proposed Controller: } \omega_{n, \text { rot,des }}=0.6 \mathrm{rad} / \mathrm{s}, \\
\zeta_{\text {rot,des }}=1.0, \Delta \zeta_{\text {pit }}=0.03\end{array}$ \\
\hline 2 & Land-based NREL 5-MW controller [21] \\
\hline 3 & Detuned NREL 5-MW controller [17] \\
\hline
\end{tabular}

Controller 1, the two-DoF-tuned controller, was implemented with a controller frequency of $0.6 \mathrm{rad} / \mathrm{s}$, a damping ratio of 1.0 and a targeted increase in the platform pitch damping ratio of 3\%. The target natural frequency of Controller 2 is also $0.6 \mathrm{rad} / \mathrm{s}$ (as is typical of land-based controllers), however, the design damping ratio is 0.7 instead of 1.0. This is due to the fact that Controller 2 gains are tuned using Eq. 27 with the absence of the $A_{\Omega}$ term. By using $\zeta_{\text {rot,des }}$ $=1.0$ for Controller 1 , the achieved gains for $k_{p}$ and $k_{i}$ are very similar for Controllers 1 and 2. Controllers 2 and 3 are set up identically, except for the target natural frequency being reduced to $0.2 \mathrm{rad} / \mathrm{s}$ for the detuned controller. This is to prevent platform pitch instabilities caused by the collective blade pitch controller, but it comes at the cost of poorer regulation of power.

For Controller 1, the filter for the nacelle velocity signal (Eq. 26) implemented in OpenFAST is shown in Figure 3. The filter was centered at a pitch natural frequency of $0.237 \mathrm{rad} / \mathrm{s}$. A value of $\Delta \omega=0.094 \mathrm{rad} / \mathrm{s}$ was found to adequately reduce noise levels while maintaining the shape of signal trends, as seen in Figure 4.

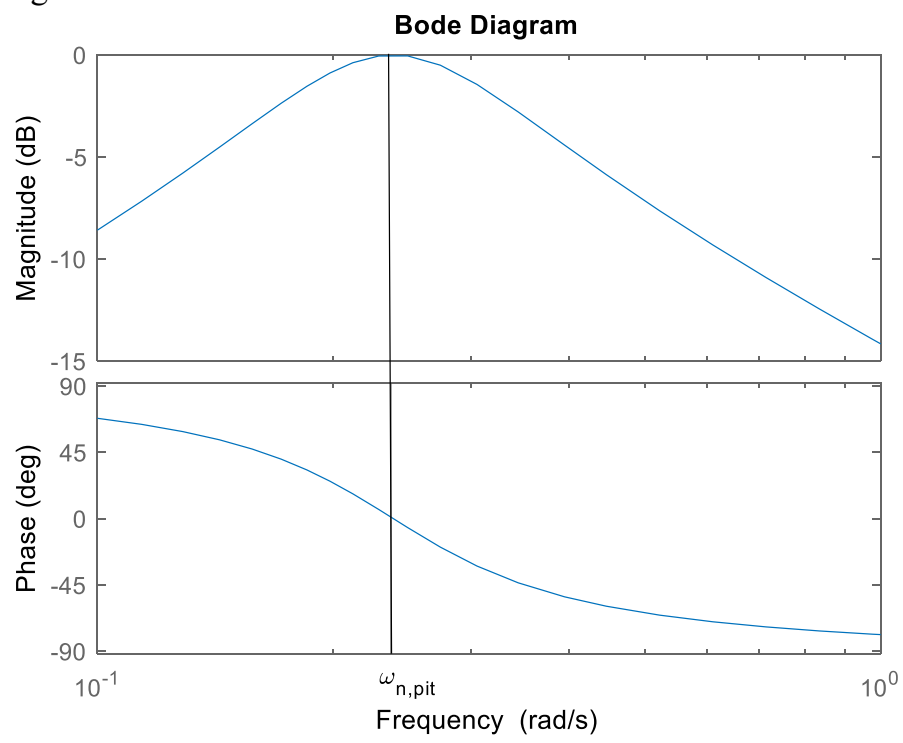

FIGURE 3: NACELLE FILTER BODE PLOT

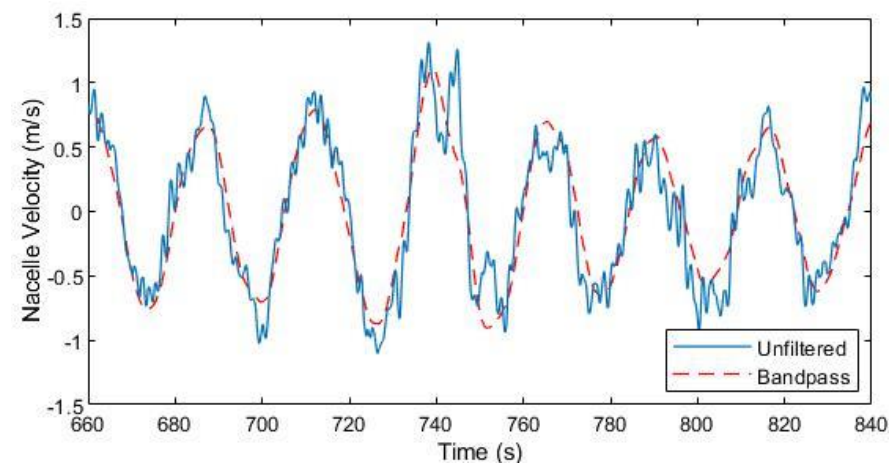

FIGURE 4: EXAMPLE TIME DOMAIN FILTER DATA

\section{RESULTS}

First, estimates of control parameter influence on the global performance of the DeepCwind OC4 semisubmersible as predicted by the two-DoF model are presented. Subsequently, the results of OpenFAST time-domain simulations are discussed for the three control schemes considered.

\section{Two-DoF Model-Predicted Behavior}

In this section, all results are based on the system properties given in Table 1 and are associated with a wind speed of $18 \mathrm{~m} / \mathrm{s}$. The gains for $k_{p}$ and $k_{i}$ are tuned using Eq. 25 as previously discussed with $\zeta_{\text {rot,des }}=1.0$.

Looking at controller behaviors predicted by the two-DoF model, several trends can be noted. One of these, seen in Figure 5 , is a relationship between the nacelle feedback gain, controller design frequency, and the platform pitching frequency.

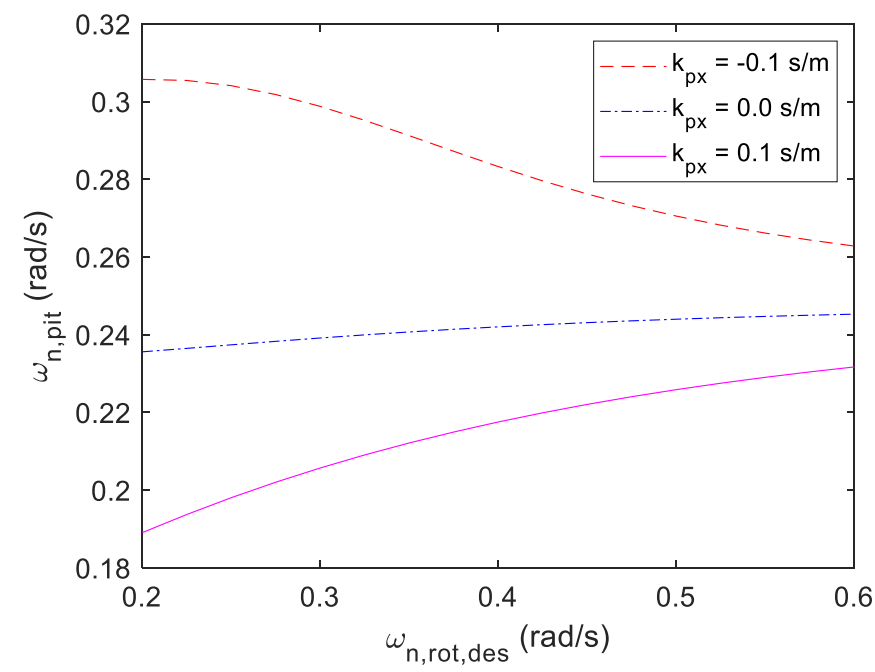

FIGURE 5: EFFECT OF CONTROLLER FREQUENCY AND NACELLE FEEDBACK ON PLATFORM PITCH NATURAL FREQUENCY

While the controller frequency has some impact on the platform pitching frequency, the nacelle feedback gain has a significant influence on the platform pitching frequency with 
larger values of $k_{p x}$ reducing the platform natural frequency. This is not entirely unexpected, as previous model testing of floating wind turbines using active blade pitch controllers has shown that controller behavior can influence platform pitch natural frequencies [25] in addition to damping out platform motion.

Further exploring the effect of the controller properties on system characteristics, the platform pitching damping ratio is examined in Figure 6 for a variety of controller options. The impact of the nacelle feedback gain was found to be dependent on the controller frequency. For higher-frequency controllers, a negative nacelle velocity feedback gain results in improved platform pitch damping. As the controller is detuned, the negative gain results in negative pitch damping, which would represent instability in the absence of viscous effects on the platform. Positive values of $k_{p x}$ are instead needed to increase damping for a detuned controller. Previous work using detuned controllers did show that a positive value of $k_{p x}$ improved platform motion performance somewhat [1]; however, to the authors' knowledge no work has indicated that pairing a negative feedback gain with standard land-based controller $k_{p}$ and $k_{i}$ gains will improve platform pitch motion. In the next subsection, OpenFAST simulations will be used to quantify if this combination of gains can be used to not only avoid platform pitch instabilities, but also smoothly regulate power.

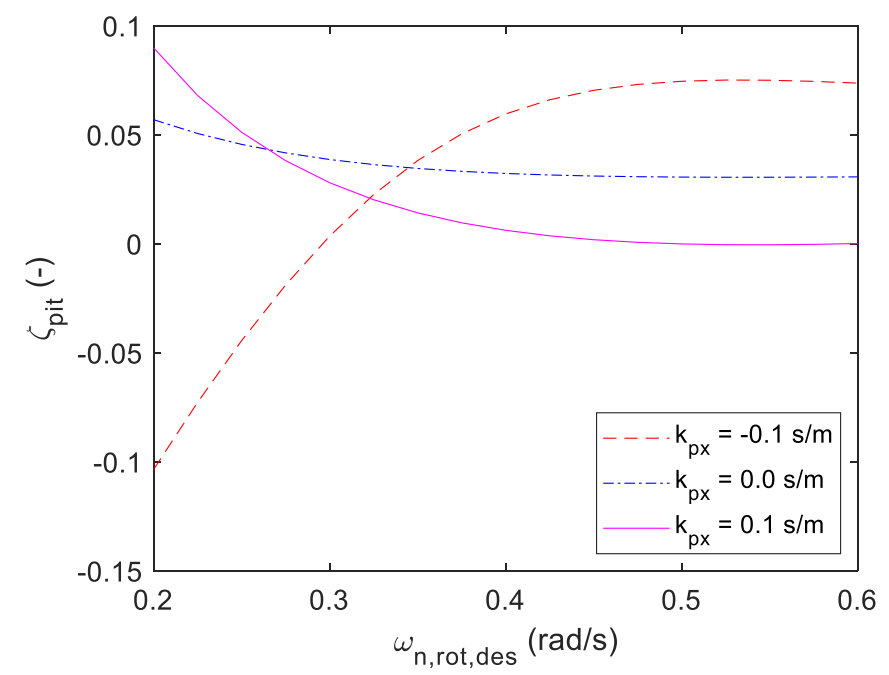

FIGURE 6: PLATFORM PITCH DAMPING AS A FUNCTION OF CONTROLLER FREQUENCY, FOR SEVERAL NACELLE GAIN SETTINGS

\section{Time-Domain Simulation}

The controller gain schedules for Controller 1 used for OpenFAST simulations are shown in Figure 7 . The proportional and integral gains of the new controller do not deviate far from the traditional land-based controller settings, which is to be expected given that they have the same controller frequency. The nacelle feedback term to achieve the increased platform damping was negative, which is consistent with the trends defined in Figure 6.
Using the control schemes described in Table 3, OpenFAST simulations were run for all of the environments and seeds noted in Table 2. In addition, a set of simulations was also performed for the land-based controller (Controller 2) in the instance where the tower base was fixed. These results provide context for how the various floating wind turbine system controllers perform relative to a standard, land-based configuration. Example time-domain data for a $12-\mathrm{m} / \mathrm{s}$ wind, just above the rated wind speed of the NREL 5-MW turbine, is shown in Figure 8.

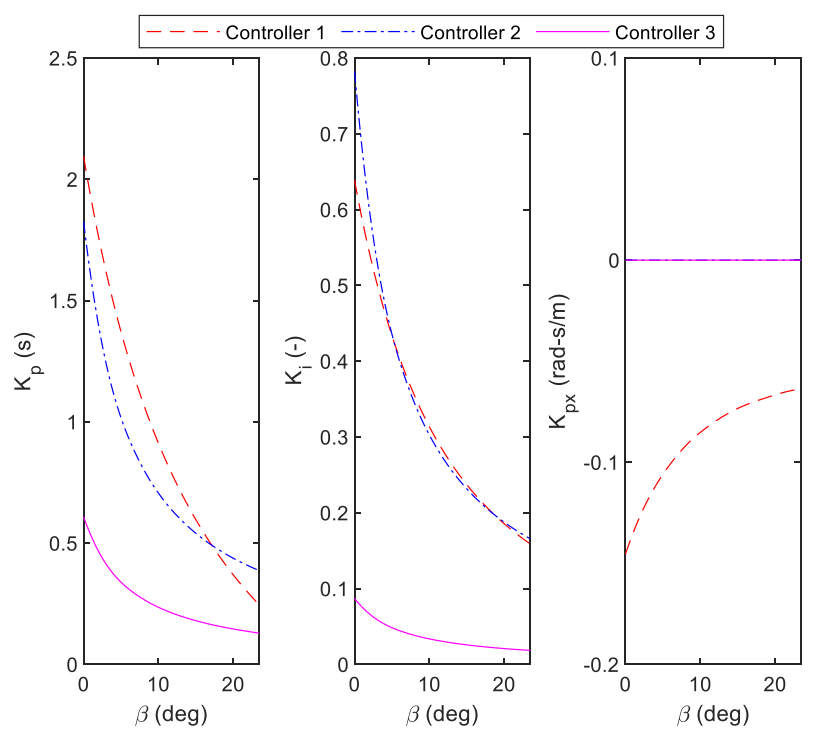

FIGURE 7: GAIN SCHEDULES
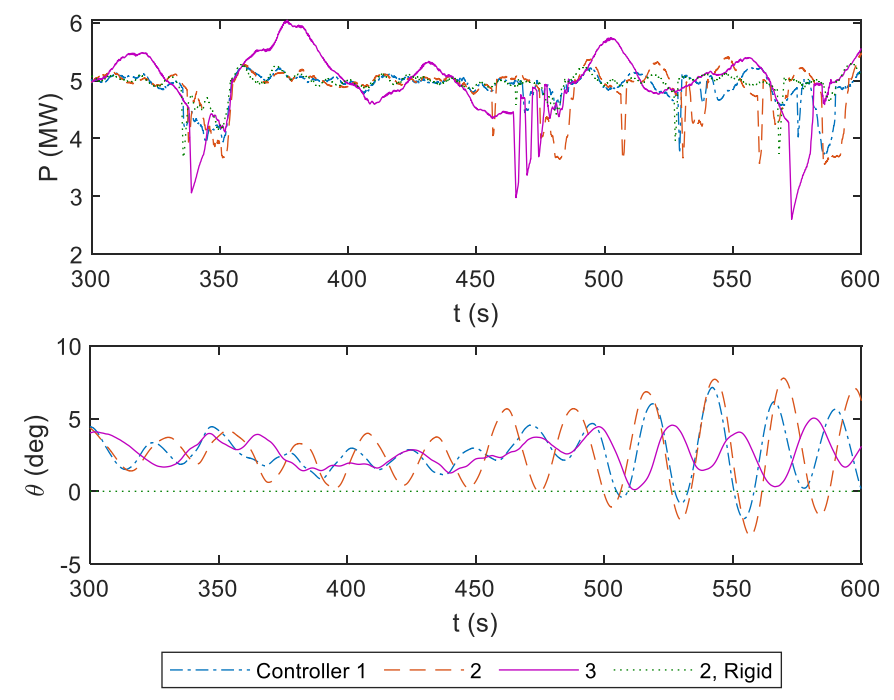

FIGURE 8: EXAMPLE TIME DOMAIN DATA FOR POWER (ABOVE) AND PLATFORM PITCH (BELOW) FOR A 12-M/S WIND CASE

It can be noted that the controller tuned with the two-DoF model (Controller 1) results in less power variability than the detuned controller (Controller 3) while also restraining platform 
pitch better than the standard NREL 5-MW controller (Controller 2). For a fuller picture, Figure 9 shows a box plot over all seeds for generator power, rotor speed, blade pitch, platform pitch, and nacelle acceleration in $12-\mathrm{m} / \mathrm{s}$ wind conditions. The mean values are noted in red, the $25^{\text {th }}$ and $75^{\text {th }}$ percentiles are in blue, and the extremes are noted in black.
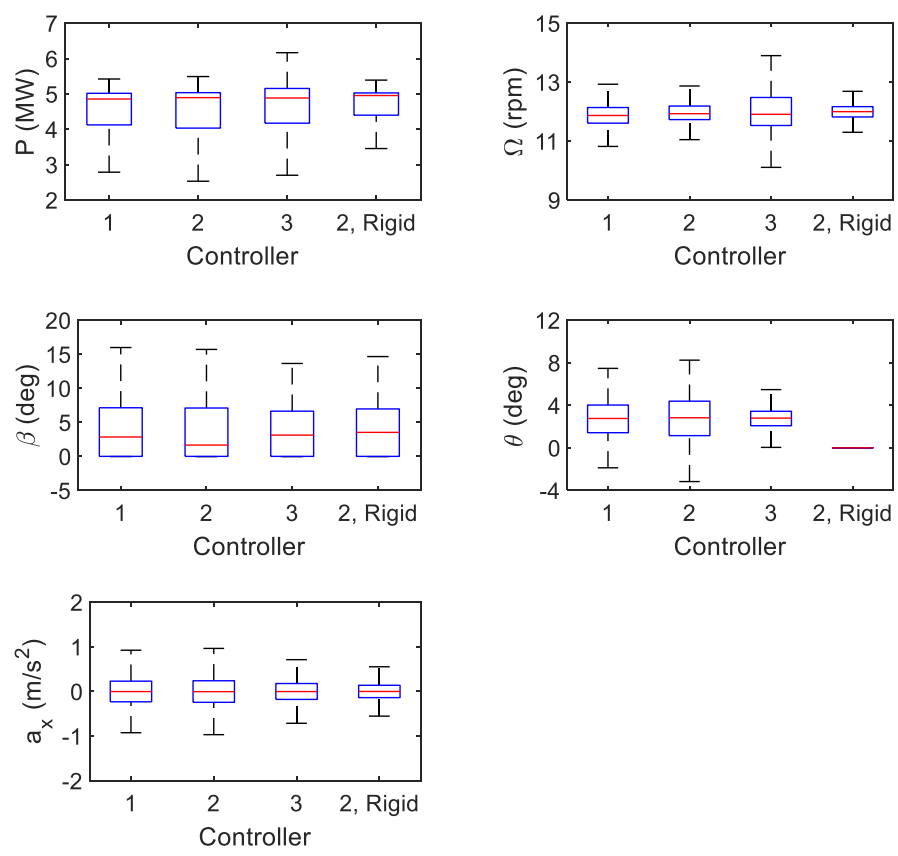

FIGURE 9: CONTROLLER PERFORMANCE, 12-M/S WIND CASE

Controller 1 achieves power and rotor speed regulation comparable to Controller 2, but exhibits $18 \%$ less range in extreme values for platform pitching. Interestingly, Controller 2 has a markedly lower median blade pitch angle than the other controllers, which would contribute to its increased platform pitch motion due to the amplified forces acting on the turbine. Controller 3 performs the best of the floating controllers at managing platform pitch and nacelle accelerations, but is the least successful at power and rotor speed regulation.

Controller performance was also examined under $18-\mathrm{m} / \mathrm{s}$ mean wind conditions, with statistics over all seeds of the chosen metrics shown in Figure 10. Trends are similar to the $12-\mathrm{m} / \mathrm{s}$ case, though slightly more pronounced. Controller 3 has the largest variation in power output $(171 \%$ more range between extremes than Controller 1). Unlike the $12-\mathrm{m} / \mathrm{s}$ wind case, Controller 1 sees less deviation in platform pitch than either of the other floating wind turbine controllers considered for the $18-\mathrm{m} / \mathrm{s}$ condition. Extreme values in power production for Controller 1 were found to have a $23 \%$ wider spread than those of the rigid-mounted, traditionally controlled turbine for this loading condition. This appears reasonable considering the dynamic effects added with the floating hull.
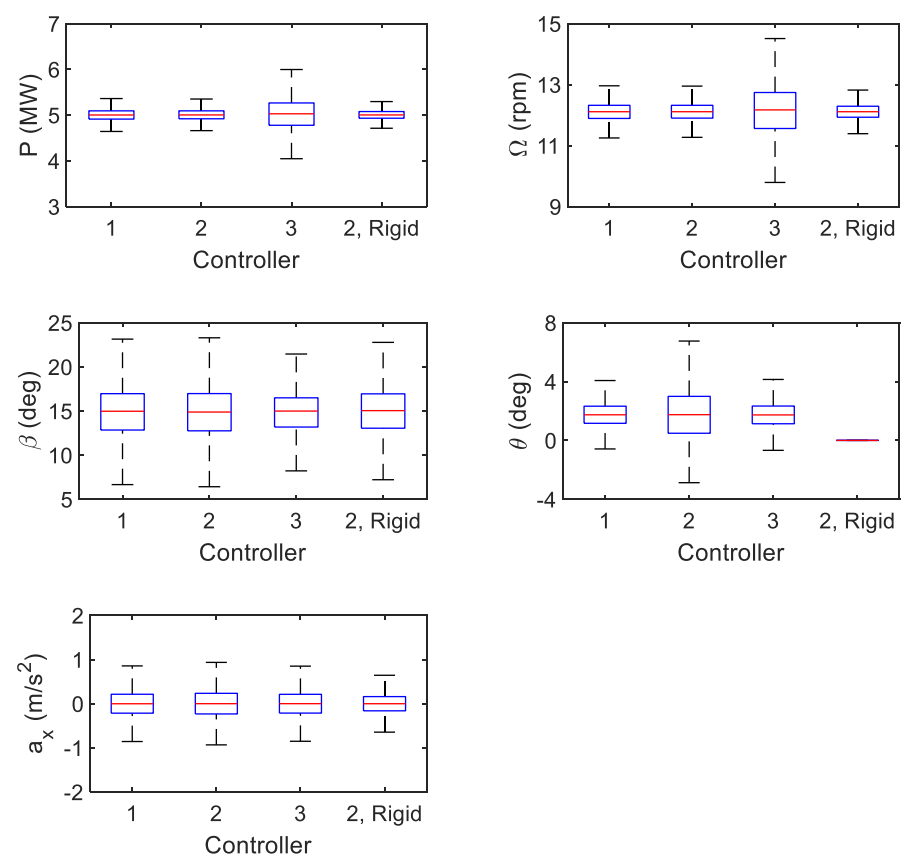

FIGURE 10: CONTROLLER PERFORMANCE, 18-M/S WIND CASE

\section{CONCLUSION}

A tuning method for a collective blade pitch controller for floating wind turbines was developed with the goal of being simple to tune. The two-DoF model used in this method indicates a negative correlation between the nacelle velocity feedback gain and platform pitch frequency. The effect of this feedback gain on platform pitch damping was found to be dependent on the natural frequency of the controller. At landbased frequency settings, a negative feedback gain increases damping; the opposite is true for detuned controllers.

For the examined OpenFAST time-domain load cases, the proposed tuning method was shown to exhibit power regulation performance comparable to a standard wind turbine PI controller and platform pitch stability more similar to a detuned controller, with a minimal increase in blade pitching activity. Power deviation was not far from that of a similar land-based turbine setup.

Future work in this area will include testing the tuning method on other turbines and platforms to ensure that similar performance is achieved, and possibly automating the gain scheduling process through tools like ROSCO to further simplify its use.

\section{ACKNOWLEDGEMENTS}

This work was authored in part by the National Renewable Energy Laboratory, operated by Alliance for Sustainable Energy, LLC, for the U.S. Department of Energy (DOE) under Contract No. DE-AC36-08GO28308. Funding provided by the U.S. Department of Energy Office of Energy Efficiency and Renewable Energy Wind Energy Technologies Office. The views expressed in the article do not necessarily represent the 
views of the DOE or the U.S. Government. The U.S.

Government retains and the publisher, by accepting the article for publication, acknowledges that the U.S. Government retains a nonexclusive, paid-up, irrevocable, worldwide license to publish or reproduce the published form of this work, or allow others to do so, for U.S. Government purposes.

The authors would like to gratefully acknowledge the support of the National Science Foundation through Award Number 1832876, as well as the financial support provided to Eben Lenfest by an AVANGRID Fellowship. The authors would also like to acknowledge the support and input of National Renewable Energy Laboratory staff in developing this work.

\section{REFERENCES}

[1] J. Jonkman, "Influence of Control on the Pitch Damping of a Floating Wind Turbine," NREL/CP-500-42589, National Renewable Energy Laboratory, Golden, CO, 2008.

[2] Larsen, T.J., and Hanson, T.D., "A Method to Avoid Negative Damped Low Frequent Tower Vibrations for a Floating, Pitch Controlled Wind Turbine," Journal of Physics: Conference Series, vol. 75, 2007.

[3] A. Scholbrock, P. Fleming, D. Schlipf, A. Wright, K. Johnson and N. Wang, "Lidar-Enhanced Wind Turbine Control: Past, Present, and Future," in Proceedings, 2016 American Control Conference, Boston, MA, 2016.

[4] D. Schlipf, F. Sandner, S. Raach, D. Matha and P. W. Cheng, "Nonlinear Model Predictive Control of Floating Wind Turbines," in Proceedings of the Twenty-Third International Offshore and Polar Engineering Conference, Anchorage, AK, 2013.

[5] D. Schlipf, E. Simley, F. Lemmer, L. Pao and P. W. Cheng, "Collective Pitch Feedforward Control of Floating Wind Turbines Using Lidar," in Proceedings of the Twenty-fifth International Ocean and Polar Engineering Conference, Kona, Big Island, HI, 2015.

[6] S. Nalkavar, J. v. Wingerden, P. Fleming and G. v. Kuik, "Integrating Robust Lidar-Based Feedforward with Feedback Control to Enhance Speed Regulation of Floating Wind Turbines," in Proceedings, 2015 American Control Conference, Chicago, IL, 2015.

[7] K. Magar and M. Balas, "Adaptive Individual Blade Pitch Control to Reduce Platform Pitch Motion of a Floating Offshore Wind Turbine: Preliminary Study," in Proceedings of the 2014 ASME Conference on Smart Materials, Adaptive Structures, and Intelligent Systems, Newport, RI, 2014.

[8] F. Lemmer, D. Schlipf and P. Wen Cheng, "Control Design Methods for Floating Wind Turbines for Optimal Disturbance Rejection," Journal of Physics: Conference Series, vol. 753, 2016.

[9] V. Pascu, S. Kanev and J. van Wingerden, "Adaptive
Tower Damping Control for Offshore Wind Turbines," Wind Energy, vol. 20, pp. 765-781, 2017.

[10] K. Kakita, H. Naoyuki and K. Konishi, "PI Controller Gain Tuning with FRIT in Collective Blade Pitch Control of Floating Offshore Wind Turbines," in Proceedings, 15th International Conference on Control, Automation, and Systems, Busan, Korea, 2015.

[11] B. Fischer, "Reducing Rotor Speed Variations of Floating Wind Turbines by Compensation of Non-Minimum Phase Zeros," IET Renewable Pwer Generation, vol. 7, no. 4, pp. 413-419, 2013.

[12] B. Fischer and P. Loepelmann, "Balancing Rotor Speed Regulation and Drive Train Loads of Floating Wind Turbines," Journal of Physics: Conference Series, vol. 753, 2016.

[13] P. Fleming, A. Peiffer and D. Schlipf, "Wind Turbine Controller to Mitigate Structural Loads on a Floating Wind Turbine Platform," in Proceedings of the ASME 35th International Conference on Ocean, Offshore, and Arctic Engineering, Busan, South Korea, 2016.

[14] M. Lackner, "An Investigation of Variable Power Collective Pitch Control for Load Mitigation of Floating Wind Turbines," Wind Energy, vol. 16, pp. 519-528, 2013.

[15] B. Skaare, T. Hanson and F. Nielsen, "Importance of Control Strategies on Fatigue Life of Floating Wind Turbines," in Proceedings of the 26th International Conference on Offshore Mechanics and Arctic Engineering, San Diego, CA, 2007.

[16] N.J. Abbas et al., "An Update to the National Renewable Energy Laboratory Baseline Wind Turbine Controller," in Proceedings, NAWEA WindTech 2019, Amherst, MA, 2019.

[17] A. Robertson et al., "Definition of the Semisubmersible Floating System for Phase II of OC4," NREL/TP-500060601, National Renewable Energy Laboratory, Golden, CO, 2014.

[18] J. Jonkman, "Dynamics Modeling and Loads Analysis of an Offshore Floating Wind Turbine," NREL/TP-50041958, National Renewable Energy Laboratory, Golden, $\mathrm{CO}, 2007$.

[19] S. Rao, "Mechanical Vibrations, Fifth Edition," Upper Saddle River, NJ, Pearson, 2011, p. 501.

[20] N. Nise, Control Systems Engineering, 6th Ed., Jefferson City, MO: John Wiley \& Sons, 2011.

[21] J. Jonkman et al., "Definition of a 5-MW Reference Wind Turbine for Offshore System Development," NREL/TP 500-38060, National Renewable Energy Laboratory, Golden, CO, 2009.

[22] H. Zumbahlen, "Phase Response in Active Filters," Analog Dialogue, vol. 50, no. 1, pp. 26-29, 16 March 2016.

[23] B. Koo, A. Goupee, R. Kimball and K. Lambrakos, "Model Tests for a Floating Wind Turbine on Three 
Different Floaters," Journal of Offshore Mechanics and Arctic Engineering 136(2):020907, 2014.

[24] P. Fleming, I. Rossetti, A. Wright and D. Arora, "Evaluating Methods for Control of an Offshore Floating Turbine," in Proceedings, ASME 33rd International Conference on Ocean, Offshore, and Arctic Engineering, San Fransisco, CA, 2014.

[25] A. Goupee, R. Kimball and H. Dagher, "Experimental Observations of Active Blade Pitch and Generator Control Influence on Floating Wind Turbine Response," Renewable Energy, vol. 104, pp. 9-19, 2017. 